\title{
Food sanitation practices in restaurants of Ramallah and Al-Bireh district of Palestine
}

\author{
I.A. Al-Khatib ${ }^{1}$ and S.M.Al-Mitwalli ${ }^{1}$
}

$$
\text { عصام أحمد إلخطيب، سوزام الطعام محمد المتولي منطقتَي رام الله والبيرة في فلسطين }
$$

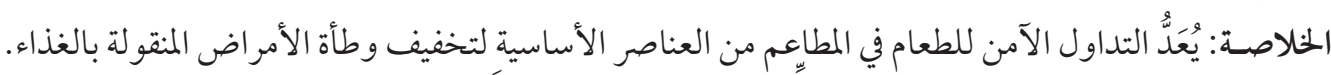

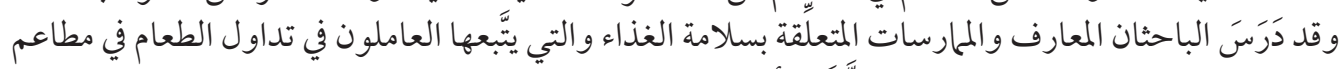

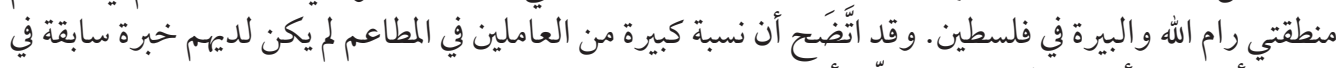

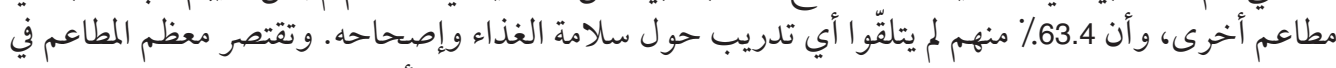

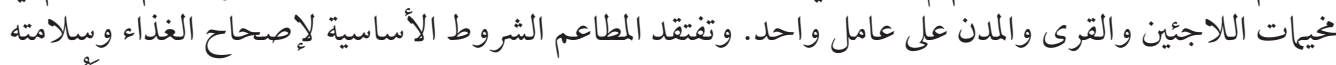

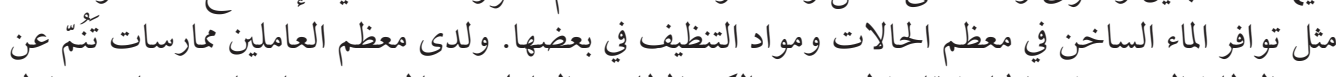

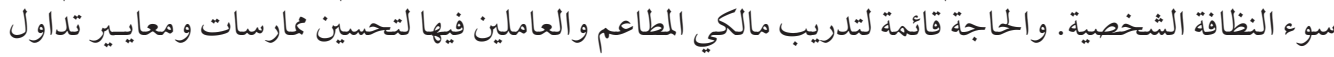

ABSTRACT Safe handling of food in restaurants is a basic element in the reduction of foodborne illness. We investigated knowledge and practices about food safety by food-handlers in restaurants in Ramallah and Al-Bireh district of Palestine. A high proportion of workers in the restaurants had no previous experience in other restaurants and $63.4 \%$ had received no training on food sanitation and safety. Most of the restaurants in the refugee camps, villages and towns had only 1 worker. Restaurants lacked basic conditions for food sanitation and safety, such as hot water in most and cleaning materials in some. Many workers had poor personal hygiene practices. Training is needed for restaurant owners and staff to improve food handling practices and standards.

Pratiques en matière d'hygiène alimentaire dans les restaurants du district de Ramallah-AlBireh (Palestine)

RÉSUMÉ L'application de principes de sécurité à la manipulation des aliments dans les restaurants est un élément déterminant aux fins de la réduction des maladies d'origine alimentaire. Nous avons étudié les connaissances et les pratiques en matière de sécurité sanitaire des aliments chez les personnes qui manipulent la nourriture dans des restaurants du district de Ramallah-Al-Bireh (Palestine). Une forte proportion des employés de ces restaurants n'avait jamais travaillé dans un restaurant auparavant et $63,4 \%$ n'avaient reçu aucune formation à l'hygiène alimentaire et à la sécurité sanitaire des aliments. Dans la plupart des restaurants situés dans les camps de réfugiés, dans les villages et les villes, les effectifs se résumaient à une personne. Les conditions élémentaires d'hygiène et de sécurité sanitaire étaient inexistantes ; dans la plupart de ces restaurants, il n'y avait pas d'eau chaude et dans certains, pas de matériel de nettoyage. De nombreux employés n'observaient pas de bonnes pratiques d'hygiène personnelle. II est nécessaire de former les propriétaires et le personnel des restaurants afin d'améliorer les pratiques et les normes de manipulation des aliments.

${ }^{1}$ Institute of Community and Public Health, Birzeit University, West Bank, Palestine (Correspondence to I.A. Al-Khatib: ikhatib@birzeit.edu).

Received: 18/06/06; accepted: 25/02/07

المجلة الصحية لشرق المتوسط، منظمة الصحة العالمية، المجلد الخنامس عشر، العدد ع، 9 +. 


\section{Introduction}

Food contamination in restaurants results from proliferation of microbes at unsafe temperatures, handling by infected persons who practice unsanitary habits and direct exposure to microbes that cause the disease [1]. Good sanitation practices in restaurants are important not only to reduce direct and cross-contamination of food but also to increase the morale and efficiency of workers and to satisfy the customers from an aesthetic point of view [2].

Food-handlers need proper hygiene practices concerning cleanliness of hands and work clothes and correct methods of handling food and utensils. They must not smoke cigarettes while preparing or serving food [3] or work in any area of a food service establishment while infected with any communicable disease [4]. Training the staff on the principles of handling food in all its stages is important [5]. It has been reported that most outbreaks of foodborne diseases result from faulty food handling practices [6,7]. For example, improper food handling practices have contributed to approximately $97 \%$ of foodborne illnesses in homes and food-service establishments in the United States of America [8].

In order to decrease foodborne illness it is essential to gain an understanding of the prevailing food safety practices, beliefs and knowledge of food-handlers [9]. This paper presents data on food-handlers' beliefs about food safety and their self-reported practices in restaurants in the Ramallah and Al-Bireh district in Palestine, and the extent to which the workers are complying with the sound principles of food-handling in all its stages.

\section{Methods}

The fieldwork ran from December 2004 to March 2005. The study included all 236 res- taurants in Ramallah and Al-Bireh district. The sample was $202(85.6 \%)$ restaurants, as $34(14.4 \%)$ refused to participate. Each restaurant was visited, some at a mutually agreed time and others without prior warning, and all available food-handlers, including managers, were interviewed to complete the questionnaire. A food-handler was defined as "any person involved in a food business who handles or prepares food whether open (unwrapped) or packaged (food includes drink and ice)" [10]. A total of 308 workers were recruited in restaurants in the following localities: $243(78.8 \%)$ in Ramallah and Al-Bireh cities, 53 (17.2\%) in villages and towns, and $12(3.9 \%)$ in refugee camps.

Two semi-structured questionnaires were prepared. The first was for foodhandlers and the second was for field observations. Pilot field visits were conducted in 5 restaurants and 8 workers were interviewed, and some modifications were made to the questionnaires. The workers' questionnaire contained personal questions including age and years of experience, daily practices of handling foods, work clothes and hygiene, training and instructions received, as well as questions about insects and rodents present and the general cleanliness of the restaurant. Participants were assured that their responses would be kept in the strictest confidence and would remain anonymous. All the questionnaires were completed and returned during the visit. This method of data collection ensured that the questionnaires were filled out; the participants did not look information up, were able to answer the questions in their work environment, were able to ask the researcher if they had any queries and could be reassured that other employees/employers would not have access to their responses [11].

The second questionnaire was for field observations about food handling and gen-

المجلة الصحية لشرق المتوسط، منظمة الصحة العالمية، المجلد الخامس عشر، العلد ع، 9 + • 
eral hygiene in the restaurants, such as the cleanliness of workers' hands and nails and cleanliness of the kitchen and service rooms and the food storage areas.

Data obtained from the workers' questionnaire were coded and entered into computer using SPSS, version 12. The data were analysed and cross-tabulated. The chi-squared test was used for statistical analysis.

\section{Results}

\section{Selected characteristics of food- handlers in restaurants}

Of the 308 food-handlers, $43.5 \%$ were aged 19-29 years (Table 1). The youngest was 14 years and the oldest was 70 years, with a mean of 31.6 years. The level of education was low among workers in the restaurants (Table 1).

A high proportion of workers (124, $40.3 \%$ ) reported working for the first time in restaurants, and 43 (34.7\%) of these had experience of 1 year or less (Table 2). When asked about the training they received during their work in restaurants, only $37.6 \%$ of the food-handlers reported that they had received training. Most of them believed

\begin{tabular}{|c|c|c|}
\hline Variable & No. & $\%$ \\
\hline \multicolumn{3}{|l|}{ Age (years) } \\
\hline $14-18$ & 17 & 5.5 \\
\hline $19-29$ & 134 & 43.5 \\
\hline 30-39 & 89 & 28.9 \\
\hline $40+$ & 68 & 22.1 \\
\hline \multicolumn{3}{|l|}{ Education leve/ ${ }^{a}$} \\
\hline Preparatory or less & 130 & 42.3 \\
\hline Secondary & 119 & 38.8 \\
\hline Post-secondary & 58 & 18.9 \\
\hline Total & 308 & 100.0 \\
\hline
\end{tabular}

that just working in the restaurant constituted training.

Most of the food-handlers in restaurants worked in the cities, and this was proportional to the number of restaurants in the cities. Most of the restaurants in the villages and towns had a small surface area with a small number of food-handlers (Table 3). In refugee camps, $63.6 \%$ of restaurants had only 1 food-handler who was usually the owner of the restaurant, and most of the restaurants with more than 2 food-handlers were found in the cities.

\section{Practices, health and personal hygiene of food-handlers in the restaurants}

Hand-washing

Most food-handlers reported that they always washed their hands before starting work, when moving between work with unready and ready foods, and after using the toilet; only $10.5 \%$ reported never washing their hands. Regarding the way that the food-handlers washed their hands, 22.1\% reported washing their hands with water only and $76.5 \%$ reported washing their hands with water and soap. This contradicts what was observed during the fieldwork, where cleaning materials were not available near the hand-washing sinks of the kitchens (14.2\% of restaurants) and toilets $(37.3 \%)$. When asked about hand-washing after coughing and sneezing, $68.0 \%$ of the food-handlers reported that they always washed their hands and $21.6 \%$ that they sometimes did.

\section{Smoking}

A "no smoking" sign was found in only 2 of the 202 surveyed restaurants. Over half of the food-handlers were smokers $(170 / 306$, $55.6 \%)$. Out of these, $149(87.6 \%)$ reported that they did not smoke while preparing and serving food. However, a number of food-

المجلة الصحية لشرق المتوسط، منظمة الصحة العالمية، المجلد الخنامس عشر، العدد ع، 9 +. 


\begin{tabular}{|c|c|c|c|c|c|c|}
\hline \multirow[t]{2}{*}{$\begin{array}{l}\text { Years of } \\
\text { experience }\end{array}$} & \multicolumn{2}{|c|}{$\begin{array}{l}\text { Food-handlers who worked in } \\
\text { restaurants for the first time }\end{array}$} & \multicolumn{2}{|c|}{$\begin{array}{l}\text { Food-handlers who had } \\
\text { worked in restaurants before }\end{array}$} & \multicolumn{2}{|c|}{ Total $^{a}$} \\
\hline & No. & $\%$ & No. & $\%$ & No. & $\%$ \\
\hline$\leq 1$ & 43 & 34.7 & 4 & 3.1 & 47 & 18.6 \\
\hline $2-3$ & 30 & 24.2 & 6 & 4.7 & 36 & 14.3 \\
\hline$>3$ & 51 & 41.1 & 118 & 92.2 & 169 & 67.1 \\
\hline Total & 124 & 100.0 & 128 & 100.0 & 252 & 100.0 \\
\hline
\end{tabular}

${ }^{a}$ Data on years of experience missing for 56 food-handlers.

handlers who said they did not smoke were observed smoking by fieldworkers, suggesting that the percentage of food-handlers who smoke while working was under-reported. Some of the smokers $(12,7.1 \%)$ mentioned that they sometimes smoked while working, and $8(4.7 \%)$ admitted that they always smoked while preparing and serving food.

Food handlers' health during food handling When food-handlers were asked how they behaved when they had a health problem such as influenza, $172(56.0 \%)$ reported that they left work during sickness, while $76(24.8 \%)$ reported that they sometimes took leave, and $54(17.6 \%)$ said that they never took leave under any circumstances (5 answers were inapplicable). Regarding the reasons for taking leave, $51.5 \%$ reported that it was to rest during sickness and $36.7 \%$ to avoid infecting others and only $1.5 \%$ to avoid contaminating the food $(10.3 \%$ had other reasons). Most of those who reported that they never left said it was because they could not leave the restaurant, and $11.5 \%$ reported that they were not allowed by the employer to take leave.

\section{Workwear}

When asked about the availability of workwear and their adherence to wearing it, aprons were available for $252 / 307$ (82.1\%), haircovers for $171(55.7 \%)$, gloves for 200 $(65.1 \%)$ and aprons, haircovers and gloves for $136(44.3 \%)$.

\section{Personal hygiene of the food-handlers}

Some of the personal hygiene practices reported by the food-handlers are summarized in Table 4. Most of the food-handlers did not wear necklaces, while $46(15.0 \%)$ and $40(13.1 \%)$ said that they wore rings and kept long nails during work, always or sometimes, respectively.

\section{Workers' reports of infestation}

Food-handlers were asked if rodents or insects such as cockroaches were present in the restaurant: $66(21.6 \%)$ reported that rodents or insects were sometimes seen in

\begin{tabular}{|c|c|c|c|c|c|c|c|c|c|c|c|c|}
\hline \multirow[t]{3}{*}{ Locality } & \multicolumn{12}{|c|}{ No. of food-handlers in restaurant } \\
\hline & \multicolumn{2}{|c|}{1} & \multicolumn{2}{|c|}{2} & \multicolumn{2}{|c|}{3} & \multicolumn{2}{|c|}{ 4-6 } & \multicolumn{2}{|c|}{$7+$} & \multicolumn{2}{|c|}{ Total } \\
\hline & No. & $\%$ & No. & $\%$ & No. & $\%$ & No. & $\%$ & No. & $\%$ & No. & $\%$ \\
\hline City & 18 & 12.5 & 51 & 35.4 & 23 & 16.0 & 36 & 25.0 & 16 & 11.1 & 144 & 100.0 \\
\hline Town or village & 16 & 34.0 & 18 & 38.3 & 11 & 23.4 & 2 & 4.3 & 0 & 0.0 & 47 & 100.0 \\
\hline Camp & 7 & 63.6 & 4 & 36.4 & 0 & 0.0 & 0 & 0.0 & 0 & 0.0 & 11 & 100.0 \\
\hline Total & 41 & 20.3 & 73 & 36.1 & 34 & 16.8 & 38 & 18.8 & 16 & 7.9 & 202 & 100.0 \\
\hline
\end{tabular}


Table 4 Practices of food-handlers in restaurants concerning use of workwear (when available) and self-cleanliness

\begin{tabular}{|c|c|c|c|c|c|c|}
\hline \multirow[t]{3}{*}{ Practice } & \multicolumn{6}{|c|}{ Frequency of practice } \\
\hline & \multicolumn{2}{|c|}{ Always } & \multicolumn{2}{|c|}{ Sometimes } & \multicolumn{2}{|c|}{ Never } \\
\hline & No. & $\%$ & No. & $\%$ & No. & $\%$ \\
\hline \multicolumn{7}{|l|}{ Workwear practice ${ }^{a}$} \\
\hline Wear apron $(n=252)$ & 166 & 65.9 & 63 & 25.0 & 23 & 9.1 \\
\hline Wear haircover $(n=171)$ & 105 & 61.4 & 43 & 25.1 & 23 & 13.5 \\
\hline Wear gloves $(n=199)$ & 94 & 47.2 & 88 & 44.2 & 17 & 8.5 \\
\hline $\begin{array}{l}\text { Wear apron, haircover and gloves } \\
(n=136)\end{array}$ & 55 & 40.4 & 9 & 6.6 & 1 & 0.7 \\
\hline \multicolumn{7}{|l|}{ Other practices } \\
\hline Wear necklace during work $(n=307)$ & 18 & 5.9 & 5 & 1.6 & 284 & 92.5 \\
\hline Wear ring during work $(n=307)$ & 41 & 13.4 & 5 & 1.6 & 261 & 85.0 \\
\hline Have long nails during work $(n=307)$ & 14 & 4.6 & 26 & 8.5 & 267 & 87.0 \\
\hline
\end{tabular}

$n=$ number of responses to item.

the restaurant and $240(78.4 \%)$ said they were not.

\section{Discussion}

Almost $73 \%$ of the restaurants in villages and towns had only 1 or 2 food-handlers, whereas in the cities $52.1 \%$ of the restaurants had 3 or more food-handlers. This may be attributed to the diversity of meals served in the city restaurants, which require a variety of experiences with food preparation on the one hand and food serving and meeting the requirements of customers on the other.

Most of the food-handlers in the restaurants we surveyed were young people with a low level of education. Many (40.4\%) were working in that restaurant for the first time. Most of the food-handlers who had gained experience from working in other restaurants had worked there for more than 3 years.

In spite of having some years of experience, $62.4 \%$ of the food-handlers in restaurants had never received any training about personal hygiene. Owners and managers of restaurants themselves may lack basic knowledge about food sanitation and safety, and it should be the role of the health inspectors from the Ministry of Health to improve safety and sanitation awareness among food-handlers, restaurant owners and managers. However, there are no explicit national requirements and standards for food safety legislation or guidelines.

The absence of a special area for the food-handlers in most of the restaurants encouraged them to smoke in areas of food preparation, as they spend most of their working time there. Smoking transfers contaminants from mouth to hands and cigarettes emit particles that contribute to food contamination [12]. A "no smoking" sign was found in only 2 restaurants, although smoking is not allowed in public places according to Palestinian environmental law [13]. A study conducted in the United States of America found that the amount of indoor air contamination in restaurants that are free of smoke is $84 \%$ less than that in restaurants where smoking is allowed [14]. In addition, the percentage of mortality from lung cancer among food-handlers in restaurants where smoking is allowed is $50 \%$ higher

المجلة الصحية لشرق المتوسط، منظمة الصحة العالمية، المجلد الخامس عشر، العدد ع، 9 +. 
than in other people, due to passive smoking and the absence of a smoking policy that protects nonsmokers from exposure to passive smoking $[15,16]$.

Another factor that contributes to food contamination in restaurants is food handling by workers while sick. Microbes can be transmitted to food from dirty hands and from sneezing and coughing unless precautions are taken [17]. Although Palestinian labour law requires employers to pay foodhandlers a full sick-leave at the employer's expense for up to 14 days and to pay half the wage for another 14 days [18], the general economic situation in Palestine is difficult and food-handlers may fear loss of wages in case of sick leave.

Availability of haircovers and gloves in this study was low. Food-handlers and restaurant owners may not know about the importance of workwear, and owners may not want the expense of providing such equipment. Food-handlers in restaurants frequently use aprons in order to keep their clothes clean, but even when aprons were available, food-handlers did not always wear them. Proper workwear is also an important factor for preventing contamination by disease and for giving customers a sense of security and satisfaction.

Cleaning materials were absent near the hand-washing sinks of the kitchen and toilets ( $14.2 \%$ and $37.3 \%$ respectively). Hands should be washed according to good hygiene practices in order to reduce the risk of food contamination, and water should come from a safe source, both hot and cold, and with appropriate pressure. Toilets and handwashing facilities should be convenient, accessible, well-designed and appropriately installed. The absence of hot water in many of the restaurants, which is necessary for proper hand-washing and sanitizing of food equipment and utensils, contributes to the risk of food contamination [19].
The food-handlers reported that they sometimes or always detected insects and rodents in the restaurants. Restaurants should have no detectable presence of insects, rodents, birds, turtles or other animals, and openings to the outside air should be protected. A favourable environment for insect and rodent proliferation is enhanced by the lack of adequate buildings, storage areas, kitchen, water supply, sanitation and solid waste management facilities, as well as poor attitudes and practices of foodhandlers found in many of the restaurants in this study.

The findings of this study can be interpreted in relation to a report of a high percentage of unacceptable food samples from the restaurants of Ramallah and AlBireh district; $67.4 \%, 40.2 \%$ and $66.7 \%$ of samples tested had unacceptable levels of total aerobic count, total coliforms and faecal coliforms respectively, according to the Palestinian and WHO standards [Ramallah and Al-Bireh Directorate, Environmental Health Division, unpublished data]. Other research conducted in the province of Karak in Jordan showed samples of diary products had high viable counts of coliforms and other contaminants which indicate serious faults in production hygiene, unsatisfactory sanitation and unsuitable storage temperature $[20]$.

\section{Conclusions and recommendations}

The hygiene and food sanitation knowledge and practices of food-handlers was genenrally unsatisfactory among the restaurants surveyed. Restaurant inspections should ensure awareness among patrons and foodhandlers about food sanitation and safety in restaurants. All factors that influence the uniformity and reliability of routine restau- 
rant inspections by health inspectors should be modified. This could be achieved by policies and regulations designed to ensure periodic training, inspection and systematic standardization among inspection evaluations. Implementation of new public health laws approved by the Palestinian National Authority legislative council is a priority. Upgrading the quality control system, including legislation reform, developing explicit guidelines, improving inspection and laboratory testing and taking appropriate punitive or corrective measures should be a priority.

Training in food hygiene that embodies the concept of risk should be implemented in restaurants in order to emphasize to foodhandlers, especially those in managerial positions, the level of risk associated with their business. This training should be implemented with the supervision of health inspectors.

\section{Acknowledgements}

The authors would like to thank all who participated in this study and assisted in its completion. We thank the Swiss Agency for Development and Cooperation for financial support of this study.

\section{References}

1. Cardinale E et al. Risk factors for contamination of ready-to-eat street-vended poultry dishes in Dakar, Senegal. International journal of food microbiology, 2005, 103:157-65.

2. Powell SC et al. The impact of training on knowledge and standards of food hygiene: a pilot study. International journal of environmental health research, 1997, 7:329-34.

3. Benjamin CA, Stanton AG. Smoke-free ordinances increase restaurant profit and value. Contemporary economic policy, 2004, 22(4):520-5.

4. Foodborne illness prevention program [online article]. State of Oregon Department of Human Services, Office of Environmental Public Health (http:// oregon.gov/DHS/ph/foodsafety, accessed 23 November 2008).

5. Why food safety training? [online article]. National Environmental Health Association (http://www.nehatraining.org/ why_food_safety_training.htm, accessed 9 November 2008).
6. Ehiri JE, Morris GP. Hygiene training and education of food handlers: does it work? Ecology of food and nutrition, 1996, 35:243-51.

7. Bryan FL. Risks of practices, procedures and procedures that lead to outbreaks of food borne diseases. Journal of food protection, 1988, 51:663-73.

8. Howes $\mathrm{M}$ et al. Food handler certification by home study: measuring changes in knowledge and behaviour. Dairy food and environmental sanitation, 1996, 16:73744.

9. Health education in food safety. Geneva, World Health Organization, 1988 (WHO/ EHE/FOS/88.7).

10. Clayton DA et al. Food handlers' beliefs and self-reported practices, International journal of environmental health research, 2002, 12:25-39.

11. United Kingdom Department of Health. Industry guide to good hygiene practice: catering guide. London, Chadwick House Group, 1997. 
12. Environmental tobacco smoke [online factsheet]. National Safety Council (http:// www.nsc.org/resources/Factsheets/environment/tobacco_smoke.aspx, accessed 9 November 2008).

13. Environmental law number 7. Ramallah, Palestine, Palestinian National Authority, 1999.

14. Secondhand smoke: worker health. Americans for Nonsmokers' Rights Foundation [online factsheet] (http://www.no-smoke. org/htmlpage.php?id=27, accessed 9 November 2008).

15. Shopland DR et al. Disparities in smokefree workplace policies among food service workers, Journal of occupational and environmental medicine, 2004, 46(4):347-56.

16. Siegel M. Involuntary smoking in the restaurant workplace: a review of employee exposure and health effects. Journal of the American Medical Association, 1993, 270:490-3.

17. Consumer guide on food hygiene and sanitation at food outlets [online factsheet]. eHomemakers (http://www.ehomemakers.net/en/article.php?id=1014, accessed 9 November 2008).

18. Labor law number 7. Chapter 2: work leaves. Article 79. Ramallah, Palestine, Palestinian National Authority, 2002.

19. Diamond M. Shutdown policies vary from department to department. The press of Atlantic City, 2 October, 2004. (http:// www.pressofatlanticcity.com/news/ reports/032104REST4WEB.cfm, accessed 9 November 2008).

20. Al-Tahiri R. A comparison on microbial conditions between traditional dairy products sold in Karak and same products produced by modern dairies. Pakistan journal of nutrition, 2005, 4(5):345-8. 